\title{
The Effectiveness of Low-Vision Rehabilitation on Participation in Daily Living and Quality of Life
}

\author{
Ecosse L. Lamoureux, ${ }^{1}$ Julie F. Pallant, ${ }^{2}$ Konrad Pesudovs, ${ }^{3}$ Gwyn Rees, ${ }^{1}$ \\ Jennifer B. Hassell, ${ }^{1}$ and Jill E. Keeffe ${ }^{1,4}$
}

Purpose. To evaluate the effectiveness of a multidisciplinary low-vision rehabilitation program on quality of life evaluated by the Impact of Vision Impairment (IVI) instrument.

\begin{abstract}
Methods. First-time referrals to low-vision clinics were assessed before and after rehabilitation (3-6 months). Rasch analysis was used to estimate the three IVI subscale and overall values on an interval scale. A mixed between-within subjects ANOVA was used to identify whether presenting visual acuity had an interaction effect with rehabilitation change. Cohen $d$ values were used to estimate the magnitude of the change and the standardized response mean (SRM) procedure was selected to determine the clinical significance of the rehabilitationinduced changes.
\end{abstract}

REsults. One hundred twenty-four women and 68 men (mean age, 80.3 years) completed the rehabilitation. Most had agerelated macular degeneration $(62 \%, 119)$ and were moderately to severely vision impaired $(<6 / 18 ; 78 \%, 149)$. After rehabilitation, significant improvements were recorded for the overall IVI score $(P=0.006)$ and two subscales: reading and accessing information and emotional well-being $(P=0.007$ and 0.009 , respectively). No significant improvement was found on the mobility and independence subscale $(P=0.07)$. The magnitude of the postintervention improvement was found to be relatively moderate (Cohen $d=0.17-0.30$ ) and clinically modest $(\mathrm{SRM}=0.22-0.42)$.

Conclusions. Significant improvements in overall quality of life and two specific areas of daily living in people with low vision were found, although the magnitude and clinical significance of the rehabilitation-induced gains were modest. Further investigation in other models of low-vision rehabilitation is needed to optimize quality of life gains in people with low vision. (Invest Ophthalmol Vis Sci. 2007;48:1476-1482) DOI: 10.1167/iovs.06-0610

From the ${ }^{1}$ Department of Ophthalmology, Centre for Eye Research Australia, The University of Melbourne, East Melbourne, Victoria, Australia; ${ }^{2}$ Faculty of Life and Social Sciences, Swinburne University of Technology, Melbourne, Victoria, Australia; the ${ }^{3} \mathrm{NH} \& M R C$ (National Health and Medical Research Council) Centre for Clinical Eye Research, Flinders University and Flinders Medical Centre, Bedford Park, SA, Australia; and ${ }^{4}$ Vision CRC, Sydney, NSW, Australia.

Supported by the Jack Brockhoff Foundation and the Victoria Lions Foundation. JEK is a recipient of the Royal Victorian Eye and Ear Wagstaff Fellowship and ELL holds the National Health and Medical Research Council (Australia) Public Health Fellowship.

Submitted for publication June 6, 2006; revised November 14 and December 12, 2006; accepted February 7, 2007.

Disclosure: E.L. Lamoureux, None; J.F. Pallant, None; K. Pesudovs, None; G. Rees, None; J.B. Hassell, None; J.E. Keeffe, None

The publication costs of this article were defrayed in part by page charge payment. This article must therefore be marked "advertisement" in accordance with 18 U.S.C. $\$ 1734$ solely to indicate this fact.

Corresponding author: Ecosse L. Lamoureux, Centre for Eye Research Australia, Department of Ophthalmology, University of Melbourne, Locked Bag 8, East Melbourne, Victoria 8002, Australia; ecosse@unimelb.edu.au.
Tn Australia, the number of people aged 60 years or greater is expected to double by 2020, and a parallel increase in vision impairment is anticipated. ${ }^{1}$ Compromised vision significantly reduces participation in activities of daily living and visually intensive tasks and increases the risk of having depression and hip fractures, needing community and/or family support, nursing home placement, and a low self-rating of health. ${ }^{2-11}$ It has been estimated that $90 \%$ of individuals with vision impairment have useful residual vision, which could benefit from lowvision rehabilitation programs. ${ }^{12}$ Low-vision rehabilitation involves the provision of devices or training techniques for the enhancement of residual vision and devices or techniques for performing tasks without reliance on vision. Programs can vary from a comprehensive 6-week inpatient rehabilitation service to outpatient low-vision practices providing low-vision aids with minimal instruction in their use. ${ }^{13}$ Previous low-vision intervention studies have tended to focus on objective measures of functional ability. ${ }^{14-16}$ However, quantifying the outcome of low-vision rehabilitation programs on the basis of tasks alone may not adequately capture other important aspects of an individual's state. ${ }^{15}$ Rather, it has been argued that the effectiveness of low-vision rehabilitation programs should also be measured by an improvement in a person's quality of life (QOL). ${ }^{13,17,18}$ Consequently, several patient-centered QOL questionnaires have been developed and used as an essential component in outcomes research. ${ }^{11,13,19-28}$

In a few studies the effect of low-vision rehabilitation services has been investigated by using vision-specific patientcentered QOL instruments as an outcome measure. ${ }^{12,13,29,30}$ Hinds et al. ${ }^{12}$ reported significant improvements in the overall index score of the core questionnaire of the Vision-Related Quality of Life Questionnaire (VCM1) ${ }^{31}$ although only 3 of the 10 items significantly improved with rehabilitation. Similarly, only 7 of the 34 items of the National Eye Institute Visual Functioning Questionnaire $^{32}$ (NEI-VFQ 25 plus supplement) were shown to be sensitive to change after rehabilitation in a study involving partially sighted and legally blind veterans. ${ }^{13}$ This finding was contradicted by Reeves et al. ${ }^{30}$ who found no benefit of low-vision care using the VCM1 as the outcome measure. They and others have shown that enhanced models of low-vision services were no more effective than conventional low-vision rehabilitation. ${ }^{29,30}$

The limited demonstrable benefit of low-vision rehabilitation and the contradictory findings of these studies beg further investigation. Is this due to the use of insensitive instruments not specifically designed for low-vision care (e.g., NEI VFQ and VCM1) or some other attribute of the patient-centered measurement instrument? Certainly, there is a need for further studies of low-vision intervention outcomes, preferably using instruments designed for low-vision patients. An important aspect of the measurement of patient-centered outcomes is the scoring method used in questionnaires. It is critical that the traditional summary scoring of QOL scales (where response categories are arbitrarily assigned ordinal numbers which are summed across questions to generate a total score) is not used. ${ }^{33}$ Such summary scoring assumes erroneously that the value of each item represents equal difficulty and scores them 
equally. ${ }^{34}$ Furthermore, the response scale used for each item assumes that categories are equidistant for that item. ${ }^{35}$ Alternatively, Rasch analysis techniques should be used to maximize the validity and accuracy of the outcome data from the patientcentered QOL scale. Rasch analysis is based on a probabilistic measurement model that identifies a unidimensional construct, measures its validity, and provides estimates of item and person measures on an interval scale. ${ }^{36}$ The Centre for Eye Research Australia has recently revalidated its vision-specific QOL questionnaire, the Impact of Visual Impairment (IVI), using Rasch analysis. ${ }^{37}$ The re-engineered IVI has been shown to be a valid scale to measure self-reported restriction of participation in daily living activities, making it suitable to assess the outcomes of low-vision services. In this study, we therefore report the effectiveness of low-vision rehabilitation on QOL according to the Rasch re-engineered IVI.

\section{MeTHODS}

\section{Participants}

The participants were recruited between 2000 and 2002 from lowvision rehabilitation centers across the state of Victoria (Australia). Rehabilitation clients were referred from a variety of community sourcesnamely, public hospitals, private medical practice, and government and nongovernment sources. Those who volunteered themselves or were referred by a friend or family member were also accepted. Referrals generally had to be supported by a current eye report from an ophthalmologist before an appointment was made to see the optometrist at the low-vision clinic.

Adults attending low-vision rehabilitation for the first time were invited to take part in the study after details about the project were explained to them. The eligibility criteria included presenting visual acuity (PVA) $<6 / 12$ (or $>6 / 12$, with restricted fields), age $\geq 18$ years, and the ability to converse in English. All participants signed a consent form, which was needed to access low-vision rehabilitation files. Two interviews (baseline and follow-up) were undertaken to collect the IVI, sociodemographic and clinical data. Participants also completed the SF-12 to evaluate overall health. ${ }^{38}$ The follow-up assessment occurred between 3 and 6 months after rehabilitation. The assessment was not undertaken by the rehabilitation staff but by one of the coauthors (JBH). The assessments were performed in the participants' homes. Ethical approval was obtained from the Royal Victorian Eye and Ear Hospital's Human Research and Ethics Committee. The research adhered to the tenets of the Declaration of Helsinki.

\section{The Low-Vision Rehabilitation Program}

Vision Australia, a not-for-profit low-vision rehabilitation agency, provided the low-vision rehabilitation service. The multidisciplinary lowvision service for this study was implemented in six metropolitan and eight regional centers throughout Victoria (Australia). The main goal of the low-vision rehabilitation service is to help people to use their remaining vision and improve participation in daily living and QOL. The rehabilitation program begins with an initial assessment at a low-vision clinic with a member of the multidisciplinary team usually made up of occupational therapy, orientation and mobility, orthoptics, and welfare specialists. This is an opportunity for the client and their family or carer to discuss their reasons for coming to the low-vision clinic, their understanding of their vision condition and their individual needs and goals. Rehabilitation programs are tailored around this meeting and an overview of the agency services is also provided. Skilled, support, and information services are offered at this time (Table 1). Advocacy and assistance with assessing other appropriate external services are also considered.

The initial assessment is followed by a meeting with an optometrist trained in low-vision services. The optometrist assesses and discusses the person's eye condition. Near and distance vision are measured, refraction, prescription, contrast sensitivity, field loss, glare, lighting needs, and suitable low-vision aids are discussed. Magnification and different types of low-vision devices are introduced and made available for trial at home with teaching and reinforcement of their use offered. During this time, the optometrist also reinforces the other low-vision services which may be most appropriate to the person according to their self-prescribed goals by offering referral for further assistance and support from the multidisciplinary team, specialist support services, and information services (Table 1). The first visit to the optometrist generally takes about 1 hour. Peer workers (volunteers with low vision) also talk more informally about the services, and people can visit the adaptive device shop, which has open access and an interactive display of low-vision devices. Low-vision clinic consultations with the optometrist are bulk billed to the government under the medical health system. Any low-vision aids or glasses purchased are at the cost of the client. Veterans' services contribute to the costs for veterans and an indigent fund is available. There is no cost for the skilled, support, or information services.

A meeting is held each clinic day where the clients' outcomes are discussed, and a unified service and referral pathway is developed according to what the client has agreed to. This pathway plan may finish the same day at the low-vision clinic with the prescription of low-vision devices or it may expand into an extensive program where a case manager will be assigned to review outcomes, monitor the service pathway and make referrals across the multidisciplinary team (up to 6 months). The service pathway is deemed complete when the client feels satisfied that the desired outcomes have been met and cannot identify any further service needs at the time.

\section{The IVI}

The IVI was developed on a visually impaired population relevant to the issues of importance to low-vision patients-in particular, the restriction of participation in daily activities and reduced QOL. The initial 32-item IVI was either a self- or interviewer-administered instrument and has been described previously. ${ }^{11}$ Possible responses to the IVI items and their ratings were "not at all," 0 ; "rarely," 1; "a little," 2; "a fair amount," 3; "a lot," 4; and "can't do because of eyesight," 5. Subsequently, the IVI was re-engineered by using Rasch analysis to examine its response scale and internal consistency as well as to provide the true linear scoring benefits of Rasch analysis. ${ }^{37}$ This resulted in a 28 -item questionnaire with a four-category response scale for 26 items and a three-category response scale for two items. This

TABLE 1. The Components of the Multidisciplinary Low-Vision Rehabilitation Service

\begin{tabular}{llll}
\hline \multicolumn{1}{c}{ Skilled Services } & \multicolumn{1}{c}{ Support } & Information & External Referral \\
\hline Optometrist & Adaptive device shop & Braille and talking book library & Government support \\
Orthoptist & Peer support & Newsline & Community services \\
Occupational therapy & Telephone support & Radio for the print handicapped & Veterans services \\
Orientation and mobility & Day Centre & & Other low-vision agencies \\
Welfare & Recreation & & \\
Quality living groups & Companion & & \\
Tele learning & visiting & & \\
Technology service & & & \\
\hline
\end{tabular}


revised questionnaire fitted the Rasch model as shown by these statistics: item-trait interaction $\left(\chi^{2}=118, P=0.32\right)$, mean \pm SD person-fit residual values $(0.068 \pm 0.85)$, mean \pm SD item-fit residual values $(-0.203 \pm 1.45)$, and person separation reliability value ([PSR]; 0.95). The PSR (range, 0-1) indicates how well the items of the instrument separate participants in the sample. A RUMM (Rasch unidimensional measurment models) person separation reliability value of 0.7 is the equivalent of a $G$ value of 1.5 , representing the ability to distinguish two distinct strata of person ability. ${ }^{39,40}$ A value of 0.9 is equivalent to a $G$ value of 3 , with the ability to distinguish four strata of person ability. Recently, the 28-item IVI was further validated and demonstrated a three-subscale structure possessing interval level measurement characteristics. ${ }^{41}$ The three subscales are mobility and independence, 11 items; emotional well-being, 8 items; and reading and accessing information, 9 items.

\section{Statistical Analysis}

Rasch analysis was used to estimate subscale and overall values on an interval scale for each patient (RUMM2020 software; RUMM Laboratory Pty., Duncraig, WA, Australia). ${ }^{42}$ Initially, the 28 -item IVI raw scores were calculated by firstly reversing scores $[0,1,2,3,4,5]$ to $[5,4,3,2,1,0]$ to give higher IVI scores to the less impaired. Second, because of the disordered threshold, the initial six categories were collapsed to four $[3,3,2,1,0,0]$ or three $[2,2,1,1,0,0]$ as described previously. ${ }^{37} \mathrm{Next}$, the IVI rating scale and item invariance were determined. If the item and scale calibrations demonstrate stability over time (i.e., they are invariant), then differences between the person measures at pre- and postrehabilitation are valid indicators of changes in the person over time. ${ }^{43}$ Consequently, the pre- and postintervention data sets were stacked and the absence of differential item functioning (DIF) in RUMM was used to establish invariance over time. DIF occurs when groups of scores within the sample (e.g., times 1 and 2, baseline and follow-up), despite equal levels of the underlying characteristic being measured (participation in daily living), respond in a different manner to an individual item. The statistical test used for detecting DIF is an ANOVA of the person item deviation residuals with person factors (e.g., time) and class intervals (e.g., group along the trait) as factors. We found no evidence of DIF for time (pre- and postrehabilitation scores), vision impairment, comorbidity, effect of comorbidity on daily living. The interval-scaled scores on the IVI derived from Rasch analysis were exported to a commercial program (SPSS software; SPSS; Chicago, IL) for further analyses. To aid interpretability, scores were converted from the Rasch logit range to a scale from 0 to 100.

Descriptive statistical analyses were performed to characterize the sociodemographic, clinical, SF-12, and IVI data of the participants. Since presenting visual acuity (PVA) was found to be significantly associated with baseline IVI values (overall and subscales), a mixed between-within subjects ANOVA was used to investigate whether the impact of rehabilitation was the same for participants with different levels of presenting visual acuity. Data were analyzed by commercial software (SPSS ver. 14.0; SPSS Science, Chicago, IL). The critical value of statistical significance was set at $P<0.05$.

Effect sizes were calculated using Cohen's $d$ coefficient. ${ }^{44}$ An effect size greater than 0.8 was considered large, $\sim 0.5$ moderate, and $<0.2$ small. The standardized response mean (SRM) procedure was used to determine whether rehabilitation-induced changes were clinically meaningful. The SRM is the ratio of individual change to the SD of that change. The SRM values of $0.2,0.5$, and 0.8 have been proposed to represent small, moderate, and large changes, respectively. ${ }^{45}$ The following formula was used to calculate SRM scores ${ }^{46}$ :

$$
\frac{x_{\mathrm{i}}-x_{0}}{\sqrt{\frac{\sum\left(d_{1}-\bar{d}\right)^{2}}{n-1}}}
$$

where $x_{0}$ is pretest score, $x_{i}$ is posttest score, $d_{i}$ is pre- to postdifference score for subject $i, \bar{d}$ is mean difference score, and $n$ is sample size.

\section{Results}

Two hundred fifty-four participants were initially assessed. At follow-up, 62 participants were unable to be assessed for reasons including death $(n=9)$, illness $(n=20)$, refusal $(n=21)$, or inability to participate $(n=12)$. Participants who completed the rehabilitation did not differ from those who failed to finish, as both groups were found to be similar in age, gender, PVA, eye disease, location, and comorbidity $(P>0.05)$.

The SF-12 scores and sociodemographic and clinical characteristics of the 192 participants who completed the study are shown in Table 2. Most of the participants were from urban areas, had AMD and moderate to severe vision impairment (85\%, 62\%, and 63\%, respectively). There was no set of goals at the rehabilitation centers from which participants could choose. Goals were expressed in the participants' own words and were therefore articulated based on the patient's understanding, knowledge and expectations of the services. One hundred twenty-seven individual goals were expressed and subsequently categorized into six main categories for statistical analyses (Table 2). The participants' mean SF-12 results at baseline were comparable to mean values reported for Americans of similar age groups ${ }^{38}$ and did not significantly change after rehabilitation ( $t$-test; $P>0.05$ ).

Analyses of the prerehabilitation data showed no significant association $(P>0.05)$ between the IVI (overall and subscale scores) and age, gender, comorbidity, geographical location, participant's goals, and duration of vision impairment. In contrast, poor PVA was associated with a worse QOL score $(r=$ $-0.21 ; P=0.01)$. After rehabilitation, there was no significant change in the participants' PVA, comorbidity and the effect of comorbidity on daily living $(P=0.79,0.31$, and 0.11 , respectively).

\section{The Components of the Low-Vision Rehabilitation}

The specific components of the low-vision service used by our participants are shown in Table 3. More than two thirds of the participants $(n=126)$ purchased at least one low-vision device. Only four patients declined to purchase reading glasses after prescription. Magnifiers and near-vision spectacles were the most frequently acquired low-vision devices $(n=90$ and 50 , respectively). Of the four types of services grouped under skilled services, the orthoptist was the most frequently used by the participants $(33.3 \%, n=65)$. Conversely, the services of the orientation and mobility specialists were the least used by the participants $(10.4 \% ; n=20)$. The mean numbers of visits for the orthoptists, occupational therapists, orientation and mobility, and welfare specialists were 4.0 (262 visits; $n=65)$, 3.4 (128 visits; $n=38$ ), 2.7 (54 visits; $n=20$ ), and $2.7(121$ visits; $n=45)$, respectively. More than a third of the participants $(n=73)$ visited the adaptive device shop. Among the information services offered, the Braille and talking book library was used by more than one fourth of our participants ( $n$ $=53)$, whereas community services $(n=21)$ were the most common external referrals.

\section{Effectiveness of the Low-Vision Rehabilitation Service}

The mixed between-within subjects ANOVA showed that PVA did not have an interaction effect with rehabilitation change for any of the IVI scores $(\mathrm{F}(3173)=0.14, P=0.93 ; \mathrm{F}(3172)=$ $0.22, P=0.88 ; \mathrm{F}(3172)=0.34, P=0.80 ; \mathrm{F}(3173)=0.13, P=$ 0.94 , for total score and the emotional well-being, reading 
TABLE 2. The Sociodemographic and Clinical Characteristics, Rehabilitation Goals, and SF-12 Scores of the 192 Participants before Rehabilitation

\begin{tabular}{|c|c|c|}
\hline \multicolumn{2}{|l|}{ Age, y (mean $\pm \mathrm{SD})$} & $80.3 \pm 13.1$ \\
\hline \multirow[t]{2}{*}{ Gender $(n, \%)$} & Female & $124(64.6)$ \\
\hline & Male & $68(35.4)$ \\
\hline \multirow[t]{5}{*}{ Cause of vision loss $(n, \%)$} & Age-related macular degeneration & $119(61.9)$ \\
\hline & Diabetic retinopathy & $23(11.9)$ \\
\hline & Glaucoma & $16(8.5)$ \\
\hline & Other retinopathies & $19(9.9)$ \\
\hline & Other & $15(7.8)$ \\
\hline \multicolumn{2}{|l|}{ Duration of impairment, $y$ (mean $\pm S D$ ) } & $6.2 \pm 9.4$ \\
\hline \multirow[t]{2}{*}{ Location $(n, \%)$} & Urban & $166(86.5)$ \\
\hline & Rural & $26(13.5)$ \\
\hline \multirow[t]{6}{*}{ Participants' goals $(n, \%)$} & To read/perform near tasks & $41(21.3)$ \\
\hline & To obtain low-vision devices & $56(29.2)$ \\
\hline & To maintain/improve general vision & $33(17.3)$ \\
\hline & To remain independent & $20(10.4)$ \\
\hline & To obtain general support & $25(13.1)$ \\
\hline & Not defined & $17(8.6)$ \\
\hline \multirow[t]{4}{*}{ PVA $(n, \%)$} & $6 / 12$ or better with restricted field & $22(11.5)$ \\
\hline & $<6 / 12-6 / 18$ & $50(26.0)$ \\
\hline & $<6 / 18-6 / 60$ & $99(51.6)$ \\
\hline & $<6 / 60$ & $21(10.9)$ \\
\hline \multirow[t]{2}{*}{ Comorbidity $(n, \%)$} & Yes & $156(81.2)$ \\
\hline & No & $36(18.8)$ \\
\hline \multirow[t]{3}{*}{ Effect of comorbidity on daily living $(n, \%)$} & None & $38(24.4)$ \\
\hline & A little & $53(33.9)$ \\
\hline & A great deal & $65(41.7)$ \\
\hline \multirow[t]{2}{*}{ SF-12 score $(\text { mean } \pm \mathrm{SD})^{*}$} & PCS-12 & $35.7 \pm 11.3$ \\
\hline & MCS-12 & $48.8 \pm 11.8$ \\
\hline
\end{tabular}

* The summary scales of the SF-12 namely the PCS-12 (physical component summary) and MCS-12 (mental component summary) were scored from 0 to 100 where 100 indicates the best possible score and 0 represents the worst possible score.

and accessing information, and mobility and independence subscales, respectively). There was, however, a main effect for rehabilitation $(\mathrm{F}(1173)=7.6 ; P=0.006)$, for which the total IVI mean logit scores values significantly improved after lowvision services (Table 4 ). The magnitude and clinical signifi-

Table 3. The Components of the Low-Vision Service Used by the Study Participants

\begin{tabular}{lr}
\hline \multicolumn{1}{c}{ Component } & $\boldsymbol{n}$ \\
\hline Low-vision devices & 1 \\
Closed circuit television & 18 \\
Bifocals & 2 \\
Telescopic device for distance & 15 \\
Distance glasses & 90 \\
Magnifiers for near tasks & 50 \\
Near vision glasses & 65 \\
Skilled services & 38 \\
Orthoptists & 20 \\
Occupational therapists & 45 \\
Orientation and mobility & 73 \\
Welfare & 7 \\
Support services & 25 \\
Adaptive device shop & \\
Day program & 53 \\
Telephone services & 1 \\
Information services & \\
Braille talking book library & 14 \\
Newsline & 21 \\
External referral services & 16 \\
General practitioners & 8 \\
Community services & 9 \\
Government support & \\
Veterans services & \\
Other low-vision services & \\
\hline
\end{tabular}

cance of the overall improvement was found to be relatively moderate with Cohen's $d$ and SRM values of 0.25 and 0.43 , respectively. Similarly, significant main effects were found at postrehabilitation for the reading and accessing information $(\mathrm{F}(1173)=6.91 ; P=0.009)$ and the emotional well-being $(\mathrm{F}(1170)=7.47, P=0.007)$ subscales, with rather moderate Cohen's $d$ and SRM (0.20-0.42). There was, however, no significant intervention effect for the mobility and independence subscale $(\mathrm{F}(1172)=3.33)$, although it tended to approach significance $(P=0.07)$. Those who took up the services of the orientation and mobility specialists and occupational therapists $(n=48)$ tended to show a greater gain on this subscale $(0.16-0.50 \operatorname{logits} ; P=0.06)$ than did those who did not (0.76-0.94 logits; $P=0.19)$.

\section{Effectiveness of the Low-Vision Rehabilitation at Subgroup Level}

There was no significant interaction effect between rehabilitation change (overall and subscales) and gender, cause of vision loss, duration of vision impairment, geographical location, participants' goals, comorbidity, and effect of comorbidity on daily living. The effect of volume of service received on rehabilitation was also investigated. Consequently, when participants categorized as having received standard care (a lowvision clinic appointment and support or training by low-vision specialists $\leq 3$ hours) were compared with those who received enhanced low-vision rehabilitation (standard care in addition to ongoing agency training or support services $>3$ hours), there was no significant interaction effect with rehabilitation change $(\mathrm{F}(1175)=0.20, P=0.878)$.

When participants were categorized according to their mild (higher tertile $>0.94$ ), moderate (intermediate tertile -0.14 0.94 ), or severe (lower tertile $<-0.14$ ) baseline level of restriction of participation, there was initially a significant 
TABLE 4. Subscale and Overall Scores at Pre- and Postrehabilitation (Logit Scores), Effect Size, and SRMs

\begin{tabular}{lcrr}
\hline \multicolumn{1}{c}{ IVI Scores } & Before Rehabilitation & After Rehabilitation & $\begin{array}{c}\text { Effect Size } \\
\text { (Cohen's } \boldsymbol{d} \text { ) }\end{array}$ \\
\hline Mobility and independence & $0.61 \pm 1.44$ & $0.86 \pm 1.49$ & 0.17 \\
Reading and accessing information & $-0.04 \pm 1.48$ & $0.27 \pm 1.62^{*}$ & 0.22 \\
Emotional well-being & $0.63 \pm 1.61$ & $1.05 \pm 1.71^{*}$ & 0.31 \\
Overall score & $0.34 \pm 1.13$ & $0.64 \pm 1.3^{*}$ & 0.30 \\
\hline
\end{tabular}

Data are the mean \pm SD. $N=192$.

* Significant improvement at follow-up $(P<0.05)$.

interaction effect $(\mathrm{F}(2174)=5.9, P=0.03)$ with rehabilitation Participants with severe $(-0.89$ to -0.27 logits $)$ and moderate $(0.40-0.60)$ baseline restriction of participation significantly improved $(P<0.05)$, whereas those with mild restriction showed no significant change (1.51-1.47; $P=0.80)$ after rehabilitation. However, when further analyses were undertaken, controlling for the baseline IVI total score to account for a potential regression toward the mean effect, ${ }^{47}$ we found no significant interaction effect $(\mathrm{F}(2173)=2.27, P=0.10)$. No significant interaction effects were also found on the three subscales after controlling for baseline values when comparing participants with baseline mild, moderate, and severe levels of restriction of participation.

\section{Discussion}

The use of Rasch analysis to evaluate patient-centered outcome measures has been strongly recommended. ${ }^{33,34}$ It has been suggested that Rasch analysis techniques used in evaluating health outcomes improve measurement precision and generate more efficient instruments by removing measurement noise in the raw data. ${ }^{48,49}$ With the exception of a limited number of trials, ${ }^{13,50-52}$ few studies have used Rasch analysis to ascertain outcomes research for low-vision rehabilitation. Using Raschtransformed IVI scores, our findings show that low-vision rehabilitation services significantly improve participation in daily living and QOL in people with low vision. Statistically significant improvements were also found on two of the three IVI subscales and provide further evidence of the effectiveness of the low-vision rehabilitation. However, the magnitude of the improvement was statistically and clinically modest, suggesting that further research in the current and other models of lowvision rehabilitation models is still needed to generate better rehabilitation-induced gains across the range of patients attending low-vision services.

Our findings differ from Reeves et al. ${ }^{30}$ who recorded no improvement in the overall score on a vision-related QOL instrument (VCM1) in participants who received conventional low-vision rehabilitation. In their study, however, the participants' visual functions (e.g., visual acuity, contrast sensitivity) deteriorated after 12 months and may have contributed to a decline in the overall score. We did not record any significant change in visual acuity, comorbidity, or the effect of comorbidity on QOL at follow-up. The lack of deterioration in these factors and a shorter intervention period ( $\sim 6$ months) may have contributed to the effectiveness of the rehabilitation program. Reeves et al. used a traditional summary scoring technique, and it would be interesting to see whether their findings persist using interval-transformed VCM1 scores.

Although significant gains were found overall and in two subscales, the magnitude of these rehabilitation gains was modest which perhaps suggests a limited effectiveness of this low-vision rehabilitation program. However, this study was uncontrolled, as it does not take into consideration the extent to which QOL may have worsened in the complete absence of low-vision services. Notwithstanding that, another reason that may explain the absence of substantial overall and subscale gains could be found in the utilization rate of the services. Although more than two thirds of the participants purchased a low-vision device, it appears that other components of the comprehensive service were not used. About one third of the participants used the skilled services, even fewer used the support services, and just over one fourth took advantage of the information services. Few external referrals were made. Whether a greater utilization of the components of the lowvision service (other than low-vision devices) would have yielded greater improvements in the IVI subscales and QOL is hypothesis and remains to be demonstrated. It is also possible that the current low-vision service model only marginally improves QOL and may not respond to all issues that are important to the visually impaired population. There is therefore still a need to investigate other models of low-vision rehabilitation likely to produce significant improvement in all needed areas of participation in daily living and QOL.

The mobility and independence subscale of the IVI was the only one not to record a significant improvement after rehabilitation. Several reasons could be offered to explain the lack of improvement in this subscale. First, few participants took up the services of the orientation and mobility specialist and occupational therapist $(n=48)$, and our findings indicate a tendency for improvement with an uptake of a combination of these services. Second, improvement in areas of mobility and safety may require a multidimensional intervention that could include components pertinent to gait, strength, physical activity and flexibility in addition to orientation and mobility. Third, several of the mobility items in this subscale can also be affected by an age-related deterioration in musculoskeletal and flexibility systems. Although the IVI items are prefixed with the statement, "In the past month how often has your eyesight made you concerned or worried about. . . ?", it is possible that a misunderstanding of the preitem statement could affect the participant's response. Finally, as shown in our previous work, ${ }^{37}$ several items of this subscale were found to be the least difficult for this population (e.g., general safety at bome and spilling or breaking things) making it rather difficult to generate substantial intervention-induced improvement.

In contrast, the emotional well-being subscale recorded the highest effect size and SRM values. Considering that the lowvision rehabilitation model used in this study does not provide an in-house vision-specific counseling service, this finding is encouraging although not unusual. For example, Horowitz et al. ${ }^{53}$ specifically examined the impact of different elements of vision rehabilitation services on depression in older adults, with vision impairment by using a pre-post design. They found that the utilization of low-vision clinical services (assessment and prescription of low-vision devices) independently contributed to a decline in depressive symptoms after 2 years. Emotional reactions to vision loss often stem from the loss of valued activities. Low-vision services can help maintain competence as well as providing hope and confidence which in turn re- 
duces the emotional impact of vision impairment. It is therefore quite possible that being involved for the first time in a low-vision rehabilitation program may have produced an improvement in emotional well-being as measured by our items. Further work is needed to confirm our finding and hypothesis.

Although there was a significant improvement in the reading and accessing information domain at follow-up, it was modest compared with substantial gains found in a similar study by Stelmack et al. ${ }^{13}$ The two studies are difficult to compare, however, as Stelmack et al. explored the effect of rehabilitation on individual items compared with rehabilitation-induced changes in the nine-item reading domain investigated in this study. In addition, our program was less intense than that of Stelmack et al., in which patients were given lodging in the hospital for periods extending between 3 and 42 days. More important, however, the follow-up assessment was undertaken immediately before the patient's discharge from the hospital. As suggested by the main author, the patients may have systematically overestimated their functional abilities in the use of the rating scale after rehabilitation as they did not have any experience with real-life activities outside the rehabilitation center.

Although it is most likely that low-vision rehabilitation was the mechanism underpinning changes in the IVI QOL scores, other factors such as the Hawthorne effect ${ }^{54}$ and cognitive dissonance $^{55}$ should be considered. The Hawthorne effect refers to a situation in which an individual's behavior is altered by the observation itself. The impact of a Hawthorne effect on the IVI scores in this study, however, would be considered minimal, as most of the participants received a standard low-vision rehabilitation that consisted of one or two interactions with the rehabilitation staff in addition to being assessed twice by our research team. Further support of this argument is evident in the fact that no difference was found on the IVI between those who received standard care and those who received enhanced or ongoing low-vision rehabilitation, indicating that more contacts with the rehabilitation staff did not contribute to better IVI performances. Similarly, cognitive dissonance states that a change in attitude or belief occurs in an attempt to be consistent with the choice taken. Patients who volunteered for the trial could justify their choice by indicating that the outcome was successful. Although this probably plays a role, its impact is likely to be greater if the main outcome measure includes asking about satisfaction, as this form of assessment directly targets justification issues. The utilization of the 28item IVI in this study, however, would mitigate the impact of cognitive dissonance, because it was administered at baseline and follow-up.

Twenty-nine participants initially agreed to be part of a control group but subsequently decided to take up low-vision services. Because of the ethical consideration of withholding rehabilitation to people with low vision, having a control group for the current investigation was not feasible. This raises the matter of the difficulty of designing and implementing a controlled trial in low-vision intervention. One possible solution to the problem would be to have a waiting-list control group. However, in Victoria (Australia) the time between referral and first visit to low-vision rehabilitation service is relatively short $(\sim 2$ weeks) making it difficult for that group to be used as control patients. Other potential groups of control patients could be those referred to low-vision rehabilitation centers but have decided to delay their visit or those who have declined services. We have found, however, that those specific patients are very often unwilling to participate in any form of baseline or follow-up assessment. Notwithstanding the difficulties associated with recruitment and some form of sampling bias, these groups potentially remain the best prospective control groups for future studies of the effectiveness of lowvision rehabilitation in Australia.

Finally, it could be argued that the lack of more substantial gains could be related to the IVI's not being responsive to change after rehabilitation. This possibility, however, is unlikely because, using the IVI and Rasch analysis techniques, it was recently demonstrated that cataract surgery improves not only overall QOL, but also specific areas of daily functioning, such as reading and accessing information, mobility, and independence, and emotional well-being in patients with early AMD. ${ }^{56}$ The magnitude of the posttreatment changes on the IVI scores was considered relatively large with Cohen's $d$ coefficients ranging between 0.61 and 0.75 .

In conclusion, with an anticipated exponential increase of people with vision impairment, the need for low-vision services is anticipated to increase substantially in the next two decades. Therefore, a critical need exists to develop and assess models of low-vision rehabilitation likely to improve the QOL of people living with low vision and implement these models to cater to this projected increase in demand. Our uncontrolled study found a significant improvement in QOL of people with low vision. However, the magnitude of the rehabilitation-induced gains was rather clinically modest. Further research into other models of low-vision rehabilitation using Rasch calibrated patient-centered outcome measures is needed, to investigate the QOL gains across a greater proportion of people with low vision.

\section{Acknowledgments}

The authors thank Vision Australia (the low-vision agency) and its staff for implementing the low-vision service program, the participants, and Nick Johnson for his data management assistance.

\section{References}

1. Taylor HR. Eye care for the future: the Weisenfeld lecture. Invest Ophthalmol Vis Sci. 2003;44:1413-1418.

2. Hassell JB, Lamoureux EL, Keeffe JE. Impact of age related macular degeneration on quality of life. Br J Opbthalmol. 2006;90:593596.

3. Klein BE, Klein R, Lee KE, Cruickshanks KJ. Performance-based and self-assessed measures of visual function as related to history of falls, hip fractures, and measured gait time. The Beaver Dam Eye Study. Opbthalmology. 1998;105:160-164.

4. Rovner BW, Ganguli M. Depression and disability associated with impaired vision: the MoVies Project. J Am Geriatr Soc. 1998;46: 617-619.

5. McCarty CA, Nanjan MB, Taylor HR. Vision impairment predicts 5 year mortality. Br J Ophthalmol. 2001;85:322-326.

6. Wang JJ, Mitchell P, Cumming RG, Smith W. Visual impairment and nursing home placement in older Australians: the Blue Mountains Eye Study. Opbthalmic Epidemiol. 2003;10:3-13.

7. West SK, Munoz B, Rubin GS, et al. Function and visual impairment in a population-based study of older adults. The SEE project. Salisbury Eye Evaluation. Invest Ophthalmol Vis Sci. 1997;38:7282.

8. Wang J, Mitchell P, Smith W, Leeder SR. Factors associated with use of community support services in an older Australian population. Aust NZ J Public Health. 1999;23:147-153.

9. Lamoureux EL, Hassell JB, Keeffe JE. The determinants of participation in activities of daily living in people with impaired vision. Am J Ophthalmol. 2004;137:265-270.

10. Lamoureux EL, Hassell JB, Keeffe JE. The impact of diabetic retinopathy on participation in daily living. Arch Opbthalmol. 2004; 122:84-88.

11. Weih LM, Hassell JB, Keeffe JE. Assessment of the impact of vision impairment. Invest Ophthalmol Vis Sci. 2002;43:927-935.

12. Hinds A, Sinclair A, Park J, Suttie A, Paterson H, Macdonald M. Impact of an interdisciplinary low vision service on the quality of life of low vision patients. Br J Ophthalmol. 2003;87:1391-1396. 
13. Stelmack JA, Stelmack TR, Massof RW. Measuring low-vision rehabilitation outcomes with the NEI VFQ-25. Invest Ophthalmol Vis Sci. 2002;43:2859-2868.

14. Nilsson UL, Nilsson SE. Rehabilitation of the visually handicapped with advanced macular degeneration: a follow-up study at the Low Vision Clinic, Department of Ophthalmology, University of Linkoping. Doc Ophthalmol. 1986;62:345-367.

15. Raasch TW, Leat SJ, Kleinstein RN, Bullimore MA, Cutter GR. Evaluating the value of low-vision services. J Am Optom Assoc. 1997;68:287-295.

16. McCabe P, Nason F, Demers Turco P, Friedman D, Seddon JM. Evaluating the effectiveness of a vision rehabilitation intervention using an objective and subjective measure of functional performance. Ophthalmic Epidemiol. 2000;7:259-270.

17. Scott IU, Smiddy WE, Schiffman J, Feuer WJ, Pappas CJ. Quality of life of low-vision patients and the impact of low-vision services. Am J Ophthalmol. 1999;128:54-62.

18. Stelmack J. Quality of life of low-vision patients and outcomes of low-vision rehabilitation. Optom Vis Sci. 2001;78:335-342.

19. Gothwal VK, Lovie-Kitchin JE, Nutheti R. The development of the LV Prasad-Functional Vision Questionnaire: a measure of performance of visually impaired children. Invest Ophthalmol Vis Sci. 2003; $44: 4131-4139$.

20. Haymes SA, Johnston AW, Heyes AD. The development of the Melbourne Low-Vision ADL Index: a measure of visual disability. Invest Ophthalmol Vis Sci. 2001;42:1215-1225.

21. Mangione CM, Berry S, Spritzer K, et al. Identifying the content area for the 51-item National Eye Institute Visual Function Questionnaire: results from focus groups with visually impaired persons. Arch Ophthalmol. 1998;116:227-233.

22. Pesudovs K, Garamendi E, Elliott DB. The Quality of Life Impact of Refractive Correction (QIRC) Questionnaire: development and validation. Optom Vis Sci. 2004;81:769-777.

23. Steinberg EP, Tielsch JM, Schein OD, et al. The VF-14. An index of functional impairment in patients with cataract. Arch Ophthalmol. 1994;112:630-638.

24. Turano KA, Massof RW, Quigley HA. A self-assessment instrument designed for measuring independent mobility in RP patients: generalizability to glaucoma patients. Invest Ophthalmol Vis Sci. 2002; $43: 2874-2881$

25. Mangione CM, Phillips RS, Seddon JM, et al. Development of the 'Activities of Daily Vision Scale': a measure of visual functional status. Med Care. 1992;30:1111-1126.

26. Bergman B, Sjostrand J. Vision and visual disability in the daily life of a representative population sample aged 82 years. Acta Ophthatmol (Copenh). 1992;70:33-43.

27. Pesudovs K, Coster DJ. An instrument for assessment of subjective visual disability in cataract patients. Br J Ophthalmol. 1998;82: 617-624

28. Massof RW, Rubin GS. Visual function assessment questionnaires. Surv Ophthalmology. 2001;45:531-548.

29. La Grow $S$. The effectiveness of comprehensive low vision services for older persons with visual impairments in New Zealand. JVIB. 2004;98:679-692.

30. Reeves BC, Harper RA, Russell WB. Enhanced low vision rehabilitation for people with age related macular degeneration: a randomised controlled trial. Br J Ophthalmol. 2004;88:1443-1449.

31. Frost NA, Sparrow JM, Durant JS, Donovan JL, Peters TJ, Brookes ST. Development of a questionnaire for measurement of visionrelated quality of life. Ophthalmic Epidemiol. 1998;5:185-210.

32. Mangione CM, Lee PP, Gutierrez PR, Spritzer K, Berry S, Hays RD. Development of the 25-item National Eye Institute Visual Function Questionnaire. Arch Ophthalmol. 2001;119:1050-1058.

33. Hewitt AW, Jeganathan VS, Kidd JE, Pesudovs K, Verma N. Influence of photodynamic therapy for age related macular degeneration upon subjective vision related quality of life. Graefes Arch Clin Exp Ophthalmol. 2006:244:971-977.
34. Pesudovs K. Patient-centered measurement in ophthalmology: a paradigm shift. BMC Ophthalmology. 2006;15;25.

35. Garamendi E, Pesudovs K, Elliott DB. Changes in quality of life after laser in situ keratomileusis for myopia. J Cataract Refract Surg. 2005;31:1537-1543.

36. Bond T, Fox C. Applying the Rasch Model: Fundamental Measurement in the Human Sciences. Hillsdale, NJ: Lawrence A. Erlbaum Associates; 2001.

37. Lamoureux E, Pallant J, Pesudovs K, Hassell J, Keeffe J. The Impact of Vision Impairment Questionnaire: an evaluation of its measurement properties using Rasch analysis. Invest Ophthalmol Vis Sci. 2006; $47: 4732-4741$

38. Ware J, Kosinski M, Keller S. SF-12: How to Score the SF-12 Physical and Mental Health Summary Scales. Lincoln, RI: Quality Metric, Inc; 1998.

39. Fisher W. Reliability statistics. Rasch Meas Trans. 1992;6:238.

40. Wright B, Master G. Rating Scale Analysis. Chicago: MESA Press; 1982.

41. Lamoureux E, Pallant J, Pesudovs K, Rees G, Hassell J, Keeffe J. The Impact of Vision Impairment questionnaire: an examination of its domain structure using Confirmatory Factor Analysis and Rasch Analysis. Invest Ophthalmol Vis Sci. 2007;48:1001-1006.

42. Andrich D, Lyne A, Sheridan B, Luo G. RUMM 2020. Perth: RUMM Laboratory; 2003.

43. Wolfe EW, Chiu CW. Measuring pretest-posttest change with a Rasch Rating Scale Model. J Outcome Meas. 1999;3:134-161.

44. Cohen J. Statistical Power Analysis for the Behavioural Sciences. Hillsdale, NJ: Lawrence A. Erlbaum; 1988

45. Crosby RD, Kolotkin RL, Williams GR. An integrated method to determine meaningful changes in health-related quality of life. J Clin Epidemiol. 2004;57:1153-1160.

46. Stucki G, Liang MH, Fossel AH, Katz JN. Relative responsiveness of condition-specific and generic health status measures in degenerative lumbar spinal stenosis. J Clin Epidemiol. 1995;48:13691378.

47. Bland JM, Altman DG. Some examples of regression towards the mean. BMJ. 1994;309:780.

48. Norquist JM, Fitzpatrick R, Dawson J, Jenkinson C. Comparing alternative Rasch-based methods vs raw scores in measuring change in health. Med Care. 2004;42:I25-I36.

49. Velozo CA, Lai JS, Mallinson T, Hauselman E. Maintaining instrument quality while reducing items: application of Rasch analysis to a self-report of visual function. J Outcome Meas. 2000;4:667-680.

50. Stelmack JA, Szlyk JP, Stelmack TR, et al. Measuring outcomes of vision rehabilitation with the Veterans Affairs Low Vision Visual Functioning Questionnaire. Invest Ophthalmol Vis Sci. 2006;47: 3253-3261.

51. Massof RW, Hsu CT, Baker FH, et al. Visual disability variables. II: the difficulty of tasks for a sample of low-vision patients. Arch Phys Med Rehabil. 2005;86:954-967.

52. Massof RW, Hsu CT, Baker FH, et al. Visual disability variables. I: the importance and difficulty of activity goals for a sample of low-vision patients. Arch Phys Med Rehabil. 2005;86:946-953.

53. Horowitz A, Reinhardt JP, Boerner K. The effect of rehabilitation on depression among visually disabled older adults. Aging Ment Health. 2005;9:563-570.

54. Mayo E. The Human Problems of an Industrial Civilization. New York: MacMillan; 1933.

55. Erickson DB, Ryan RA, Erickson P, Aquavella JV. Cognitive styles and personality characteristics strongly influence the decision to have photorefractive keratectomy. J Refract Surg. 1995;11:267274; discussion 274-281.

56. Lamoureux EL, Hooper C, Lim L, et al. Impact of cataract surgery on quality of life in patients with early age-related macular degeneration. Optom Vis Sci. In press. 